\title{
A Síntese Industrial do Amoníaco: CALCULAdoras gráficas na RESOLU- ÇÃO DE PROBLEMAS NUMÉRICOS EM EQUILÍBRIO QUÍMICO
}

\author{
Mário Valente, Helena Moreira, Joana Noronha Sá *
}

Nestanthes brios químicos para os quais a resolução analítica não é trivial (equações de ordem superior a dois). O presente método faz uso das capacidades gráficas das calculadoras hoje obrigatórias no Ensino Secundário em geral, e na disciplina bi-anual de Física e Química A (dos 10 e 11 ำ anos) em particular.

\section{INTRODUÇ̃̃o}

A escolha da síntese industrial do amoníaco (a partir do diazoto e do di-hidrogénio) como o exemplo de um processo de equilíbrio químico, no programa da disciplina de Física e Química A do Ensino Secundário [1], não recolheu um aplauso unânime pelos professores da disciplina, já que, se por um lado esta escolha se justifica devido à natureza do produto (amoníaco) que se reveste de grande importância como matéria prima utilizada em muitas indústrias, dando uma panorâmica da importância da química na vida corrente, por outro lado, no plano mais concreto da didáctica da química, não facilita a exploração de exercícios numéricos já que pode implicar a resolução de equações de ordem 4, o que está, em princípio, fora do alcance matemático dos alunos do ensino secundário.

A obrigatoriedade da utilização de calculadoras gráficas no Ensino Secundário permite, contudo, soluções ao problema acima referido pois algumas calculadoras possuem programas pré-instalados que possibilitam a resolução de equações de ordem superior a 2 .

No presente artigo propõe-se um método simples de resolução destes exercícios, que faz uso das capacidades presentes em qualquer máquina gráfica. Este método é apresentado de seguida com recurso à utilização de

\footnotetext{
* Colégio D. Duarte, Rua Visconde de Setúbal, 86, Porto, 4200-497, Portugal madmage1@yahoo.com
}

dois exemplos, fazendo uso da Calculadora gráfica Texas TI - 83 Plus.

\section{EXEMPLOS DE EXERcícIOS}

Com o fim de ilustrar o método aqui proposto recorrer-se-á aos dois exercícios-tipo a seguir apresentados.
$\left[\mathrm{N}_{2}\right]_{\mathrm{e}}=\left[\mathrm{N}_{2}\right]_{\mathrm{i}}-\Delta,\left[\mathrm{H}_{2}\right]_{\mathrm{e}}=\left[\mathrm{H}_{2}\right]_{\mathrm{i}}-3 \mathrm{x} \Delta \mathrm{e}$ $\left[\mathrm{NH}_{3}\right]_{\mathrm{e}}=2 x \Delta$, isto é, $\left[\mathrm{N}_{2}\right]_{\mathrm{e}}=1,404-\Delta$, $\left[\mathrm{H}_{2}\right]_{\mathrm{e}}=0,613-3 \mathrm{x} \Delta \mathrm{e}\left[\mathrm{NH}_{3}\right]_{\mathrm{e}}=2 \mathrm{x} \Delta, \mathrm{em}$ que $\Delta$ corresponde à variação da concentração até se atingir o equilíbrio químico (por comodidade de cálculo optou-se por escolher a variação da concentração do diazoto como $\Delta$ ).

\section{EXERCÍ́cIO 1}

Num recipiente de volume igual a $0,460 \mathrm{dm}^{3}$ colocaram-se $0,646 \mathrm{~mol}$ de diazoto e 0,282 mol de di-hidrogénio. Esperou-se que a mistura atingisse o equilíbrio, segundo:

$$
\mathrm{N}_{2}(\mathrm{~g})+3 \mathrm{H}_{2}(\mathrm{~g}) \rightleftarrows 2 \mathrm{NH}_{3}(\mathrm{~g}) .
$$

Admita que, à temperatura da experiência, a constante de equilíbrio $\left(K_{c}\right)$ para o processo considerado apresenta o valor 0,206.

A resolução deste exercício principia pelo cálculo das concentrações iniciais das espécies presentes no recipiente: $\left[\mathrm{N}_{2}\right]_{\mathrm{i}}=0,646 / 0,460=1,404$ $\mathrm{mol} / \mathrm{dm}^{3}$ e $\left[\mathrm{H}_{2}\right]_{\mathrm{i}}=0,282 / 0,460=0,613$ $\mathrm{mol} / \mathrm{dm}^{3}$.

De seguida deve reconhecer-se que até se estabelecer o equilíbrio químico a reacção mais veloz é a correspondente ao sentido directo, o que pode ser conseguido, formalmente, pelo cálculo do quociente de reacção que, neste caso, é (no instante inicial) zero. Como $Q<K_{c}$, a reacção mais veloz é a correspondente ao sentido directo.

Atingido o equilíbrio as concentrações de diazoto, di-hidrogénio e amoníaco são dadas, respectivamente, por:
Substituíndo na expressão da constante de equilíbrio tem-se:

$$
K_{c}=\frac{(2 \times \Delta)^{2}}{(1,404-\Delta) \times(0,613-3 \times \Delta)^{3}}=0,206
$$

Pretende-se conhecer o valor de $\Delta$. Para tal pode considerar-se a função:

$$
f(\Delta)=\frac{(2 \times \Delta)^{2}}{(1,404-\Delta) \times(0,613-3 \times \Delta)^{3}}-0,206
$$

e os seus zeros corresponderão às soluções matemáticas possíveis para o problema em questão. A escolha de qual o valor a aceitar é feita considerando impossível a ocorrência de concentrações negativas, o que permite seleccionar um único dos zeros da função como aquele que faz "sen- 
tido químico". Selecciona-se, em WINDOW, uma janela gráfica adequada (por exemplo, Xmin=0; Xmax=0,2 (ver Nota); $\mathrm{Xscl}=1 ; \mathrm{Ymin}=-1 ; \mathrm{Ymax}=1$; Yscl=1) e insere-se a função anterior na calculadora gráfica em $\mathrm{Y}=$ e digitase GRAPH. No écran podem reconhecer-se três dos zeros da função. Querendo, pode redimensionar-se a janela gráfica para melhor visualização. Prima-se 2nd e TRACE, isto é, seleccione-se CALC. Com o cursor escolha-se a selecção 2 (zero) e aceite-se premindo ENTER. A calculadora está pronta para proceder ao cálculo do valor do zero pretendido. Para tal deve deslocar-se o cursor (com as teclas $\leftarrow \mathrm{e} \rightarrow$ ) para seleccionar um ponto à esquerda do zero pretendido. Prima-se ENTER. Seleccione-se um ponto à direita do zero pretendido $\mathrm{e}$ prima-se duas vezes ENTER. A calculadora apresentará, no écran, o valor do zero calculado $(0,0683 \ldots)$ a que corresponde o valor pretendido de $\Delta$. As concentrações das espécies envolvidas no equilíbrio são $\left[\mathrm{N}_{2}\right]_{\mathrm{e}}=1,404$ $-0,068=1,336 \mathrm{~mol} / \mathrm{dm}^{3} ;\left[\mathrm{H}_{2}\right]_{\mathrm{e}}=0,613$ $-3 \times 0,068=0,409 \mathrm{~mol} / \mathrm{dm}^{3}$ e $\left[\mathrm{NH}_{3}\right]_{\mathrm{e}}=$ $2 \times 0,068=0,136 \mathrm{~mol} / \mathrm{dm}^{3}$.

Para confirmar os resultados é de toda a conveniência determinar o valor da constante de equilíbrio a partir das concentrações calculadas. Assim tem-se $0,136^{2} /\left(1,336 \times 0,409^{3}\right)=0,202 \approx 0,206$ o que valida os resultados obtidos.

acção é $0,068^{2} /\left(0,668 \times 0,204^{3}\right)=0,815$ $>0,206$, pelo que a reacção mais veloz (até se atingir um novo estado de equilíbrio) é a inversa. A mesma conclusão se poderia atingir usando o princípio de Le Chatelier. Contudo, os alunos devem ser alertados para o facto de a variação de pressão apenas resultar numa alteração do estado de equilíbrio se implicar uma variação correspondente do volume do recipiente (o que é o presente caso).

\section{Pode, então, escrever-se:}

$\left[\mathrm{N}_{2}\right]_{\mathrm{e}}=\left[\mathrm{N}_{2}\right]_{\mathrm{i}}+\Delta,\left[\mathrm{H}_{2}\right]_{\mathrm{e}}=\left[\mathrm{H}_{2}\right]_{\mathrm{i}}+3 \mathrm{x} \Delta \mathrm{e}$ $\left[\mathrm{NH}_{3}\right]_{e}=\left[\mathrm{NH}_{3}\right]_{\mathrm{i}}-2 \mathrm{x} \Delta$, isto é, $\left[\mathrm{N}_{2}\right]_{e}=$ $0,668+\Delta,\left[\mathrm{H}_{2}\right]_{\mathrm{e}}=0,204+3 \mathrm{x} \Delta \mathrm{e}$ $\left[\mathrm{NH}_{3}\right]_{\mathrm{e}}=0,068-2 \mathrm{x} \Delta$.

Substituíndo na expressão da constante de equilíbrio tem-se:

$$
\mathrm{K}_{c}=\frac{(0,068-2 \times \Delta)^{2}}{(0,668+\Delta) \times(0,204+3 \times \Delta)^{3}}=0,206
$$

que se pode converter na função:

$$
f(\Delta)=\frac{(0,068-2 \times \Delta)^{2}}{(0,668+\Delta) \times(0,204+3 \times \Delta)^{3}}-0,206
$$

cujos zeros corresponderão às soluções matemáticas das quais se deve seleccionar o valor que tem "sentido químico".

\section{EXERcícIO 2}

Tome como ponto de partida o equilíbrio atingido na situação referida no exercício anterior. Se o volume do recipiente duplicou (sem alteração de temperatura), quais serão agora as concentrações das espécies presentes no novo equilíbrio?

Na elaboração deste exercício considerou-se, por comodidade de cálculo, que o recipiente duplicou de volume, o que faz com que as concentrações das espécies presentes no equilíbrio anterior passem a metade. Assim tem-se momentaneamente: $\left[\mathrm{N}_{2}\right]_{\mathrm{i}}=$ $0,668 \mathrm{~mol} / \mathrm{dm}^{3} ;\left[\mathrm{H}_{2}\right]_{\mathrm{i}}=0,204 \mathrm{~mol} / \mathrm{dm}^{3}$ e $\left[\mathrm{NH}_{3}\right]_{\mathrm{i}}=0,068 \mathrm{~mol} / \mathrm{dm}^{3}$.

Se a temperatura não variou, o valor da constante de equilíbrio também se mantém em 0,206. O quociente de re-
$0,206 \ldots \approx 0,206$ o que, mais uma vez, valida os resultados obtidos.

\section{CONCLUSÃo}

O grande potencial das calculadoras gráficas é nitidamente posto em evidência no método proposto, possibilitando um rápido cálculo das concentrações de equilíbrio para qualquer ponto inicial. Consideramos que o presente método permite, por parte dos alunos, a exploração de exercícios que usualmente não são abordados, por serem presumivelmente demasiado complexos. A esta vantagem acresce que reforça, no nosso entender, o "modo químico de pensar", relativamente aos "problemas técnicos" de cálculo matemático. A sua utilização conduz ainda à aquisição de uma maior proficiência no uso das calculadoras gráficas, como instrumento bem mais poderoso do que as antigas calculadoras científicas.

\section{NotA}

A escolha do valor de $X_{\max }$ pode ser feita admitindo que o valor de $\Delta$ não pode originar concentrações negativas. Para o exemplo apresentado, tem-se que $\Delta<1,404$ e $\Delta$ $<0,613 / 3=0,204$, logo um valor razoável para $\mathrm{X}_{\max }$ poderá ser 0,2 .

\section{REFERÊNCIA}

[1] Programa da disciplina de Física e Química A (nível 2) $11^{\circ}$ ou $12^{\circ}$ anos: http://www.dgidc.min-edu.pt/programs/ prog_eg.asp
Usando a janela gráfica $X_{\min }=0 ; X_{\max }$ $=0,03$ (ver Nota); $X_{\text {scl }}=1 ; Y_{\min }=-1$; $Y_{\text {max }}=1 ; Y_{\text {scl }}=1$ pode calcular-se 0 valor de $\Delta$ como 0,0119 ..

As concentrações das espécies envolvidas no equilíbrio são agora $\left[\mathrm{N}_{2}\right]_{\mathrm{e}}=$ $0,668+0,012=0,680 \mathrm{~mol} / \mathrm{dm}^{3} ;\left[\mathrm{H}_{2}\right]_{\mathrm{e}}=$ $0,204+3 \times 0,012=0,240 \mathrm{~mol} / \mathrm{dm}^{3} \mathrm{e}$ $\left[\mathrm{NH}_{3}\right]_{\mathrm{e}}=0,068-2 \times 0,012=0,056 \mathrm{~mol} / \mathrm{dm}^{3}$.

Para confirmação dos resultados determina-se $0,044^{2} /\left(0,680 \times 0,240^{3}\right)=$ 